\title{
Importance-performance analysis of port's services quality form perspective of containerized liner shipping
}

\author{
Hassan Jafari ${ }^{a^{*}}$, Nasser Saeidi ${ }^{\mathrm{b}}$ and Mohammad Karim Karimi ${ }^{\mathrm{c}}$
}

${ }^{a}$ M.A student in Marine Transportation, Faculty of Maritime Economics and Management, Khoramshahr marine science and technology university, Khoramshahr, Iran

${ }^{b}$ Senior Lecturer in Economics, Faculty of Maritime Economics and Management, Khoramshahr University of Marine Science and Technology,

Khoramshahr, Iran

${ }^{c}$ M.A. student in Marine Transportation, Pardis, Khoramshahr marine science and technology university, Khoramshahr, Iran

\section{H R O N I C L E}

\section{Article history:}

Received January 2, 2013

Received in revised format

29 April 2013

Accepted May 12013

Available online

May 42013

Keywords:

Quality, port service

Importance Performance Analysis

Model (IPA)

Containerized liner shipping

Imam Khomeini port

\section{A B S T R A C T}

One of the important issues in port services is to evaluate the performance of the services. Without evaluating port services and their related components, these services cannot be considered desirable and its quality cannot be enhanced. However, the evaluation and the quality assurance of port services should be accomplished based on a scientific framework and a coherent framework to have desirable results. The importance-performance analysis model is an appropriate framework where each component is evaluated in terms of two dimensions of importance and performance. This study performs performance-importance analysis of ports' services quality form perspective of containerized liner shipping in the Imam Khomeini port. In this exploratory study, 150 shipping lines experts are chosen, randomly in 2012. The study identifies 28 components of quality in port services and shipping lines' experts are requested to evaluate these components in terms of two dimensions of importance and performance. Results reveal that there is a gap between the importance and performance of all port services components except three components of 6,19 and 24. In addition, the results indicate that Importance-Performance Analysis (IPA) model is capable of evaluating and assuring quality in port services and can precisely identify the strengths and weaknesses of the seaport system and provide guidance for strategy formulation for quality improvement.

\section{Introduction}

During the past few years, there have been tremendous change on sea transportation and these various changes have created rivalry circumstances among the other ports due to enhancement of demands for goods as well as economic growth. We need to provide necessary services for shipping lines and enhancement of transportation of shipping in ports will attain, automatically. Due to lack of good facilities and shipping equipment, gradually, there is a decline trend on shipping in terms of the numbers.

*Corresponding author.

E-mail addresses: hassanport53@yahoo.com (H. Jafari) 
Therefore, to assure and to maintain a high level of the market and maritime transportation, we should save this rivalry situation and enhance the satisfying services for the customers in the ports. This could be accomplished by providing optimized fields and terminating the weak spots of the transportation to keep its quality and to assure good port servicing (Beach \& Burns, 1995; Hansen \& Bush, 1999). From this point, assuring and evaluating the quality of the services are considered as important issues, which could be leading factors in the rivalry world and contentment for the customers and remedial for the port development (Arasli et al., 2005).

The evaluation and quality assurance of port services should be performed based on a scientific framework and a coherent model to have sufficient affectivity. The importance-performance analysis model is an appropriate one to use. In this model, each component is evaluated in terms of two dimensions of importance and performance (Kitcharoen, 2004). Therefore, when using importance analysis model for assessing the performance and assuring port servicing quality, the attributes should be recognized and identified to evaluate these attributes in terms of two dimensions of importance and performance. In the servicing section, the quality evaluation will be calculated during the process. Every contact of the customer is considered as an opportunity for trustworthy and satisfaction (Beach \& Burns, 1995; Hansen \& Bush, 1999). Since the services became evident in everyday life, concurrently the index of the quality servicing as a rivalry asset among the organization show up and turn this field into an active competitive market (Johnston, 1995). The major element for assuring the quality and evaluation of the existed quality and noting the deficiency are found suitable for optimized level and upgrading conditions. In this process, attributes should be identified first, then according to their importance, we initialize the adjustment activities and, because of evaluation of these attributes, importance-performance model analysis is considered, appropriately (Dolinsky \& Caputo, 1991; Martilla \& James, 1977). Martin and James (1977) originally offered this model for enhancing the quality of the services and customers satisfaction (Deng \& Pei, 2009). The importanceperformance analysis model has an advantage to determine the weakness and the strength of the functional system and it has been used in explanatory fields such as health care, financial, information and electronic training and learning.

As explained before, in this model, each attribute is evaluated by two dimensions of "importance and performance" and we use importance criteria for detecting the place in which recourses are more vital and critical for implementation (Angel et al., 2008). The importance is the reflexive indexes approximation value in the quality (Kitcharoen, 2004). Several studies have stated that there is a positive correlation between performance of attributes and customer satisfaction. thus while utilizing the Importance-performance analysis model for evaluating and assuring the quality, the components and the attributes in which pertaining to the customers, container shipping line, should be determined so that we could evaluate them from the two dimensions of importance and performance (Matzler et al., 2004; Matzler et al., 2003).

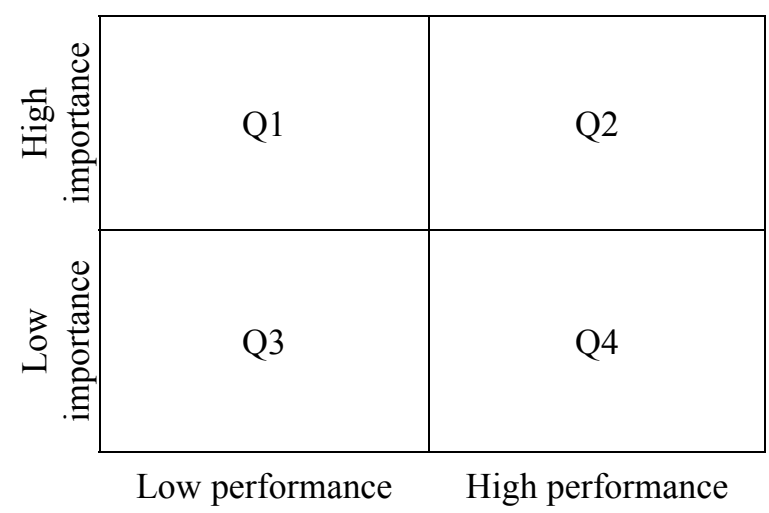

Fig. 1. Importance-performance matrix 
As mentioned, each components and attribute is evaluated in terms of two dimensions of importance and performance. The related data of the attributes are represented on a two dimensional network where the " $x$ " axis stands for importance and the " $y$ " axis stands for performance (Angel et al., 2008). This two-dimensional grid is called the importance-performance Matrix. The role of this importanceperformance matrix is to assist the determination process (Coghlan, 2012; Azzopardi \& Nash, 2012; Geng\& Chu, 2012). This matrix is used to identify the priority level of the attributes for optimized utilization (Coghlan, 2012; Azzopardi \& Nash, 2012; Geng\& Chu, 2012). In Fig. 1, part one shows high importance and low performance and everything grouped in this part has superior attribute and it should be accomplished, urgently. Part 2 shows the high importance and high performance and means that the attribute is in good and appropriate system and it should be saved. Part 3 shows low importance and low performance, which means it is not necessary to stay longer because it is out of advantage for perpetuity. Part 4 shows low importance and high performance, which means, we can obtain the better benefits from the existed resource in another domain (Matzler et al., 2004; Matzler et al., 2003).

\section{Materials and methodology}

The primary objective of this study is to evaluate and to assure the port's servicing quality from the containerized liner shipping lines in Imam Khomeini port by using the Importance-performance analysis. The instrument conducted in this study is based on a questionnaire, which pertain to analytical importance-performance. We use three questionnaires in this research according to the following description:

The first questionnaire is about the importance of 27 attributes port's servicing quality from the liner shipping's experts' perspectives. The second questionnaire is about the importance of 27 port's servicing quality from the BIK port's experts' perspective. The third questionnaire is about the performance of 27 port's servicing quality from the liner shipping's experts' perspective that asked to attribute the performance and the importance of each quality attributes. For measuring the above subjects, we used LIKRET the 5 optioned scales to obtain this matter where the lowest score was 1 and the highest score was 5. Determining the validity of the appearance of the questionnaires' content was implemented by experts' confirmation. For the final assessment of the questionnaire, the calculating Cronbach's alpha coefficient was used that its amount using SPSS software \& according to Table 1 was implemented. With regard to the calculated Cronbach's alpha coefficient for this researches' questionnaires, it is more than 0.72 , thus it can be comprehended that the validity of the questionnaire is acceptable.

\section{Table 1}

Results of Cronbach's alpha test

\begin{tabular}{lc}
\hline Questionnaire & Cronbach's alpha coefficient \\
\hline Performance questionnaire of ports' services the 27-quality components & 0.87 \\
$1^{\text {st }}$ questionnaire- significance questionnaire of ports' services the 27-quality components through & 0.82 \\
container shipping line experts' point of view & 0.95 \\
$2^{\text {nd }}$ questionnaire- significance questionnaire of ports' services the 27-quality components through & container shipping line experts' point of view
\end{tabular}

The statistical population of this study consists of the liner shipping experts in the port that have representative agency and all of the yearly crossing ships that transported and used the port services. For determining the sample size of the study, we have conducted an elementary survey by distributing the questionnaires among 30 individuals. The sample size for the survey has been determined as 150 experts. On the other side, for determining the importance of the attributes, 20 employees from BIK port's experts and managers and maritime stuff were randomly selected to attain the study. Therefore, in order to analyze the model of importance-performance, just the obtained data from the questionnaire of importance-performance from the liner shipping experts were used and employed. As mentioned earlier in this probe, the quality assurance will end up in the element and activities in which enhance the production and the quality of the servicing. In the present study, the 
importance-performance model is used to the performance symbol conducted in multi-steps as following:

First step: The importance-performance analysis in a sense is a modal of multi-criteria modal. To use this modal, we should determine the attributes, which require evaluation and analysis. In fact, the effectiveness of the importance-performance analysis modal strongly depends on analytical attributes or components. Thus, in each field, the first step in exploiting this modal is to know the relative analytical components. In this research, components were recognized as effective factors in evaluating quality-servicing attributes. We consider the existed condition of the port's servicing and previous studies in the related field of the liner shipping as well as having brain-storm sessions. Finally, 27 quality service attributes that pertains to liner shipping were chosen.

Second step: In this step, 27 determined components of the $1^{\text {st }}$ step were converted into LIKERT'S five-option performance and importance questionnaires, they were presented to some statistical communities, and they were asked to rank the attributes. Finally, the level of importance in terms of BIK port experts' view were compared with the level of importance offered by the container shipping line view.

Third step: $3^{\text {rd }}$ step is to make the significance-performance matrix where each axis is divided into two parts. In this research with respect to the fact that to attribute the components, the study implemented Likert scale of five options. To divide $\mathrm{x} \& \mathrm{y}$ axis, each axis of $\mathrm{X} \& \mathrm{Y}$ were divided in numbers of 3.5. In addition, at this stage, the results of the questionnaire were analyzed and by regarding the amounts relative to significance and presenting them on the vertical axis and calculating the average of the amounts pertaining to performance and presenting it on the horizontal axis, the position for each component of quality was determined in the Significance-Performance matrix.

Forth step: In this step, we determine the level of the performance gap for all 27 attributes in terms of the relative importance. According to (P-I) formula, the performance average of each attribute was subtracted from the importance average and the obtained score were calculated. Then, by using pair $\mathrm{t}-$ test, the relationship between the importance averages and performance averages were calculated. Whenever the meaningful relationship and the different were negative, it indicates that there was a gap between the ideal conditions, the importance attributes level, and the performance attribute level.

\section{Results}

Table 2 demonstrates the comparison of attributes in terms of the relative importance obtained by the questionnaires for all 27 multi-attributed ports' servicing quality from the container shipping line's experts and the questionnaires from all 27 multi-attributed ports' servicing quality in terms of the ports and maritime organization experts. Fig. 3 shows radar charts attributes' relative differences in terms of the two perspectives.

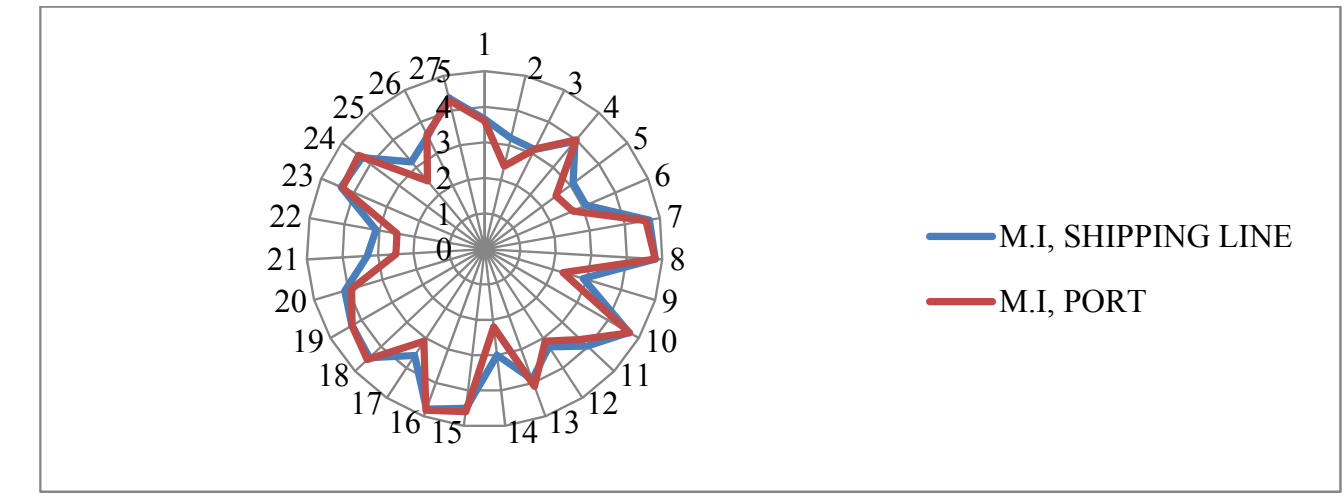

Fig. 3. The radar charts of the attributes importance difference from the two perspectives 
Table 2

The level of importance average of the quality attributes from the two perspectives of shipping experts ports and maritime organization experts

\begin{tabular}{|c|c|c|c|}
\hline NO & ATTRIBUTES & M.I, PORT & M.I, SHIPPING LINE \\
\hline 1 & Providing 24 hrs. per day and 7 day per week servicing & 3.6 & 3.65 \\
\hline 2 & suggestive added value benefits & 2.4 & 3.2 \\
\hline 3 & facility for transporting the heavy and massive goods & 3.14 & 3.13 \\
\hline 4 & fast and secure entrance of the ship into a port & 4 & 3.95 \\
\hline 5 & accessibility of the facility in the port & 2.5 & 3.1 \\
\hline 6 & MARPOL, IMO, ISPS codes and EU ( accepting the rules of & 2.7 & 3.1 \\
\hline 7 & high technology level and benefiting port mechanisms implementation & 4.6 & 4.7 \\
\hline 8 & reliable scheduling program & 4.8 & 4.8 \\
\hline 9 & benefiting from the e-commerce & 2.3 & 2.89 \\
\hline 10 & optimized multi-modal network to the port(land, railway, aerial) & 4.7 & 4.68 \\
\hline 11 & Connectivity to port hinterland & 3.7 & 3.97 \\
\hline 12 & innovation (floating terminals, containerized ports) & 3.1 & 3.29 \\
\hline 13 & the low cost of the multi-modal transportation & 4.1 & 3.9 \\
\hline 14 & night navigation possibility & 2.2 & 3 \\
\hline 15 & $\begin{array}{l}\text { Benefiting from the extra resources in the ports (fuel, fixing, water supply, cargo accounting, } \\
\text { etc.) }\end{array}$ & 4.6 & 4.5 \\
\hline 16 & High efficiency and rate of loading and unloading operation. & 4.82 & 4.78 \\
\hline 17 & the progress and the popularity of the port & 3.1 & 3.58 \\
\hline 18 & the competitive duty tariff of the port & 4.53 & 4.45 \\
\hline 19 & the high security of the port(crew and goods) & 4.3 & 4.3 \\
\hline 20 & professional human recourses in the port operation & 3.9 & 4.1 \\
\hline 21 & attendance of the documents progress in issuance and & 2.5 & 3.3 \\
\hline 22 & high quality of the port management & 2.5 & 3.1 \\
\hline 23 & the low level of disconnecting or retardation in the port's operation & 4.35 & 4.39 \\
\hline 24 & benefiting from trading and special free zone advantages & 4.41 & 4.3 \\
\hline 25 & sufficient number of storage areas and facilities & 2.5 & 3.2 \\
\hline 26 & suitable water drinking supply near the wharfs and canals & 3.6 & 3.56 \\
\hline 27 & services without of the waiting time & 4.29 & 4.36 \\
\hline
\end{tabular}

The results show that there is a huge different between the importance average in the attributes for the following subsequences:

1) The average of the second important attribute, suggestive added value benefits, was equal to 0.8 in terms of the liner shipping according to expert's perspectives, which is more than the importance attribute of the port and maritime organization expert's perspectives.

2) The average of the fifth importance attribute, the accessibility of the facilities in the port, was equal to 0.6 in terms of the liner containing shipping experts' perspectives, which is more than the relative importance attribute of the port and maritime organization expert's perspectives.

3) The average of the ninth importance attribute, benefiting from the e-commerce, was equal to 0.59 , which is more than the importance attribute of the port and maritime organization in terms of experts' perspectives.

4) The average of the fifteenth importance attribute, benefiting from the extra resources in the ports, like; fuel, fixing, water supply, cargo accounting, was equal to 0.8 , which is more than the importance attribute of the port and maritime organization experts' perspectives.

5) The average of the twenty-first importance attribute, attendance of the documents progress in issuance, was equal to 0.8 in terms of the liner containing shipping experts' perspectives, which is more than the importance attribute of the port and maritime organization experts' perspectives.

6) The average of the twenty-second importance attribute, the high quality of the port's management, was equal to 0.6 in terms of the liner containing shipping experts' perspectives, which is more than the importance attribute of the port and maritime organization experts' perspectives.

7) The average of the twenty-fifth importance attribute, supplying enough court and facility for storage, was equal to 0.7 in terms of the shipping line expert's perspectives, which is more than the importance attribute of the port and maritime organization expert's perspectives. 
The results of the importance-performance questionnaire for 27 attributes of port's servicing quality were surveyed from the liner shipping experts and the average of all attributes were calculated, their values were attained based on (P-I) formula, the performance mean of all attributes were subtracted from the importance mean, and the results were demonstrated in the Table 3 and Fig. 4.

Table 3

Results of the importance-performance questionnaire

\begin{tabular}{|c|c|c|c|c|c|}
\hline NO & ATTRIBUTES & M.P & M.I & P - I & $\mathbf{Q}$ \\
\hline 1 & Providing 24 hrs. per day and 7 day per week servicing & 3.65 & 3.65 & 0 & Q2 \\
\hline 2 & Suggestive added value benefits & 2 & 2.3 & -0.3 & Q 1 \\
\hline 3 & Facility for transporting the heavy and massive goods & 2.7 & 3.13 & -0.43 & Q 1 \\
\hline 4 & Fast and secure entrance of the ship into a port & 3.5 & 3.95 & -0.45 & Q 2 \\
\hline 5 & Accessibility of the facility in the port & 2.6 & 3.1 & -0.5 & Q 1 \\
\hline 6 & Accepting the rules of MARPOL, IMO, ISPS codes and EU & 3.1 & 3.1 & 0 & Q 2 \\
\hline 7 & High technology level and benefiting port mechanisms implementation & 2.1 & 4.7 & -2.6 & Q 1 \\
\hline 8 & Reliable scheduling program & 2.4 & 4.8 & -2.4 & Q 1 \\
\hline 9 & Benefiting from the e-commerce & 2.59 & 2.89 & -0.3 & Q 3 \\
\hline 10 & Optimized multi-modal network to the port(land, railway, aerial) & 2.3 & 4.68 & -2.38 & Q 1 \\
\hline 11 & Connectivity to port hinterland & 3.8 & 3.97 & -0.17 & Q 2 \\
\hline 12 & Innovation (floating terminals, containerized ports) & 3 & 3.29 & -0.29 & Q 1AND 2 \\
\hline 13 & The low cost of the multi-modal transportation & 2.28 & 3.9 & -1.62 & Q 1 \\
\hline 14 & Night navigation possibility & 2.5 & 3 & -0.5 & Q 1 \\
\hline 15 & $\begin{array}{l}\text { Benefiting from the extra resources in the ports (fuel, fixing, water supply, cargo } \\
\text { accounting, etc.) }\end{array}$ & 4.2 & 4.5 & -0.3 & Q 2 \\
\hline 16 & High efficiency and rate of loading and unloading operation. & 2.18 & 4.78 & -2.6 & Q 1 \\
\hline 17 & The progress and the popularity of the port & 3.3 & 3.58 & -0.28 & Q 2 \\
\hline 18 & The competitive duty tariff of the port & 2.15 & 4.45 & -2.3 & Q 1 \\
\hline 19 & The high security of the port(crew and goods) & 4.3 & 4.3 & 0 & Q 2 \\
\hline 20 & professional human recourses in the port operation & 3.9 & 4.1 & -0.2 & Q 2 \\
\hline 21 & Attendance of the documents progress in issuance and & 2 & 3.3 & -1.3 & Q 1 \\
\hline 22 & High quality of the port management & 1.9 & 3.1 & -1.2 & Q 1 \\
\hline 23 & The low level of disconnecting or retardation in the port's operation & 4.1 & 4.39 & -0.29 & Q 2 \\
\hline 24 & Benefiting from trading and special free zone advantages & 4.3 & 4.3 & 0 & Q 2 \\
\hline 25 & Sufficient number of storage areas and facilities & 2.5 & 3.2 & -0.7 & Q 1 \\
\hline 26 & Suitable water drinking supply near the wharfs and canals & 3.5 & 3.56 & -0.06 & Q 2 \\
\hline 27 & Services without of the waiting time & 3.9 & 4.36 & -0.46 & Q 2 \\
\hline
\end{tabular}

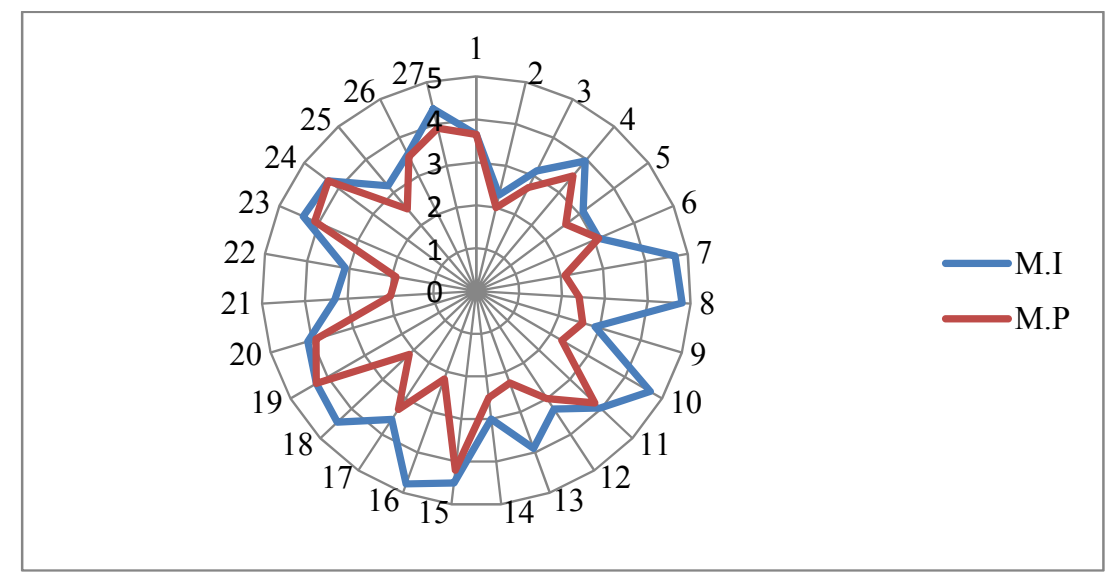

Fig. 4. The radar charts of the attributes importance and performance difference

For conducting the importance-performance matrix, each axis was subdivided into two parts and by benefiting from LIKRET 5 options scale, ' $\mathrm{X}$ and ' $\mathrm{Y}$ axis come into action where the center of the scale represents a number 3. Table 4 summarizes the results of t-test values where the null hypothesis, $\mathrm{H}_{0}: \mu_{1}=\mu_{2}$, is examined versus alternative one, $\mathrm{H}_{1}: \mu_{1} \neq \mu_{2}$. As we can see, except four cases of 1,6 , 19 and 24, in all other cases, the null hypotheses have been rejected. 
Table 4

Paired T-Test Result

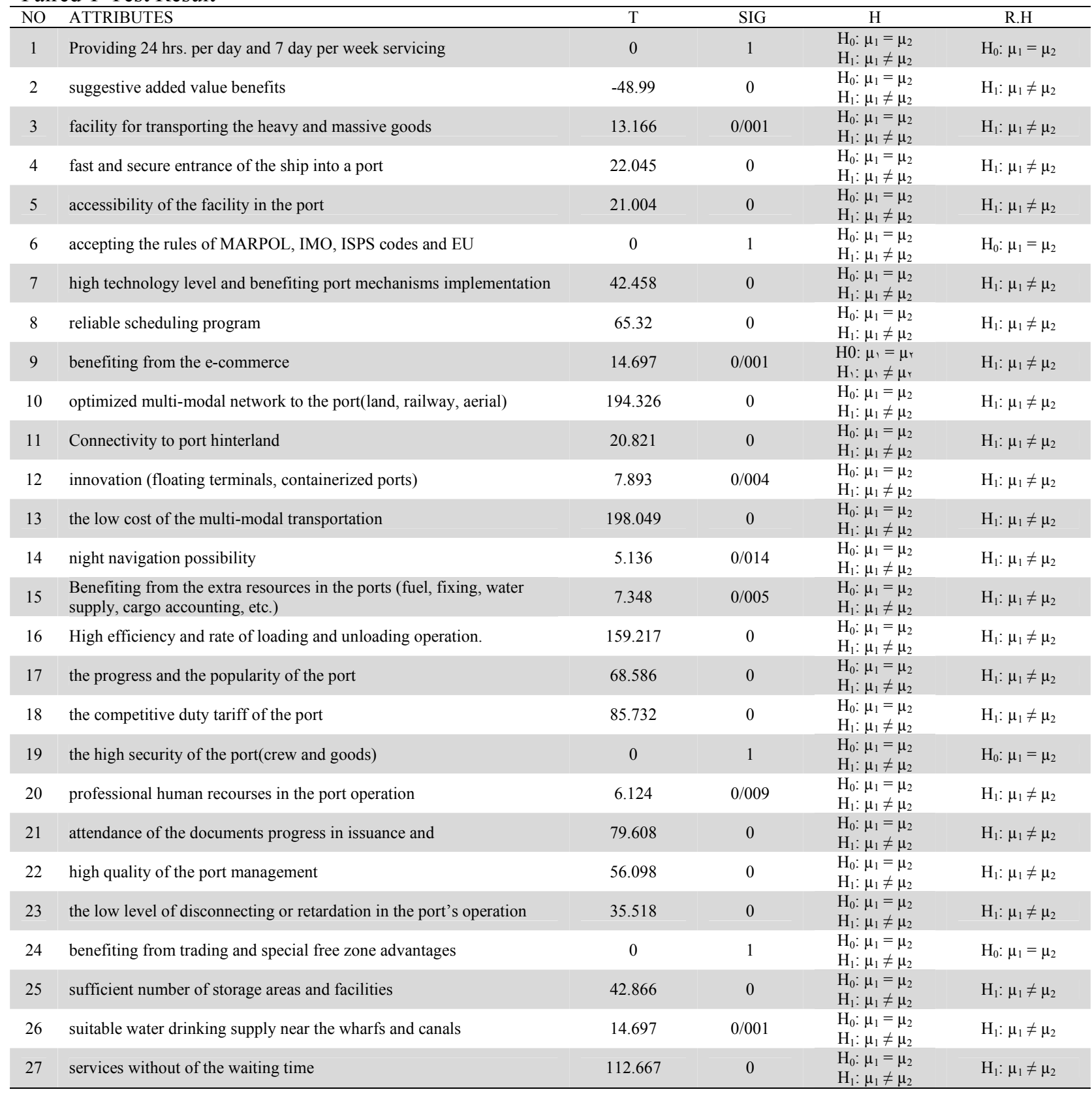

\section{Discussion and conclusion}

In this study, the port's services quality attributes were extracted in terms of the liner shipping perspectives based on 27 different attributes. The importance-performance questionnaire was generated and it was distributed to 150 individuals of liner shipping experts. Next, we have calculated the resulted values of the questionnaires using the mean of information, the related values of the importance have been represented on the vertical axis, the related values of the performance have been represented on the horizontal axis and we have considered each quality attribute signaled by the importance-performance matrix. Next, we have determined the gap for all 27 attributes from the ideal ones. Based on the results, we can conclude that those attributes located in the first part should be implemented as soon as possible because they are high in terms of relative importance and should be considered by the managers. Therefore, we can use them in the port even though they are far from the 
ideal conditions. The result of this study had shown that the analytical importance-performance model maintains high capability and reliability for evaluating and assuring the port services quality.

\section{References}

Angel, R.J., Heffernan, T.W., \& Megicks, P. (2008). Service quality in postgraduate education. Quality Assurance in Education, 16(3), 236-54.

Arasli, H., Mehtap-Smadi, S., \& Turan Katircioglu, S. (2005). Customer service quality in the Greek Cypriot banking industry. Managing Service Quality, 15(1), 41-56.

Azzopardi, E., \& Nash, R. (2012). A critical evaluation of importance-performance analysis. Tourism Management.

Beach, L.R., \& Burns, L.R. (1995). The service quality improvement strategy: Identifying priorities for change. International Journal of Service Industry Management, 6(5), 5-15.

Brooks, M. (1984). An alternative theoretical approach to the evaluation of liner shipping: Part 1, situation factors. Maritime Policy and Management, 11(1), 35-43.

Chang, Y., Lee, S., \& Tongzon, J. (2008). Port selection factors by shipping lines: Different perspectives between trunk liners and feeder service providers. Marine Policy, 32, 877-885.

Chou, C. C., Chu, C. W., \& Liang, G. S. (2003). Comparison of two models for port choice. Journal of Maritime Quarterly, 12(3), 45-61.

Coghlan, A. (2012). Facilitating reef tourism management through an innovative importance-performance analysis method. Tourism Management, 33(4), 767-775.

Deng, W.J., \& Pei, W. (2009). Fuzzy neural based importance-performance analysis for determining critical service attributes. Expert Systems with Applications, 36(2), 3774-3784.

Dolinsky, A.L., \& Caputo, R.K. (1991). Adding a competitive dimension to importance-performance analysis: An application to traditional health care systems. Health Marketing Quarterly, 8(3/4), 61-79.

Geng, X., \& Chu, X. (2012). A new importance-performance analysis approach for customer satisfaction evaluation supporting PSS design. Expert Systems with Applications, 39(1), 1492-1502.

Grosso, M., \& Monteiro, F. (2008). Relevant strategic criteria when choosing a container port - The case of the port of Genoa. Association for European Transport and Contributors, 1-21.

Hansen, E., \& Bush, R.J. (1999). Understanding customer quality requirements: Model and application. Industrial Marketing Management, 28(2), 119-130.

Johnston, R. (1995). The determinants of service quality: Satisfiers and dissatisfiers. International Journal of Service Industry Management, 6(5), 53-71.

Kitcharoen, K. (2004). The importance-performance analysis of service quality in administrative departments of private universities in Thailand. ABAC Journal, 24(3), 20-46.

Malchow, M., \& Kanafani, A. (2001). A disaggregate analysis of factors influencing port selection. Maritime Policy and Management, 28(3), 265-277.

Murphy, P., Daley, J., \& Dalenberg, D. (1992). Port selection criteria: An application of a transportation research framework. Logistics and Transportation Review, 28(3), 237-255.

Murphy, P.R., \& Daley, J.M. (1994). A comparative analysis of port selection factors. Transportation Journal, 34(1), 15-21.

Martilla, J.A., \& James, J.C. (1977). Importance-performance analysis. Journal of Marketing, 41(1), 77-79.

Matzler, K., Bailom, F., Hinter Huber, H.H., Renzl, B. and Pichler, J. (2004a). The asymmetric relationship between attribute-level performance and overall customer satisfaction: a reconsideration of the importance-performance analysis. Industrial Marketing Management, 33(4), 271-277.

Matzler, K., Sauerwein, E., \& Heischmidt, K.A. (2003). Importance-performance analysis revisited: The role of the factor structure of customer satisfaction. The Service20 Industries Journal, 23(2), 112-129.

Murdy, S., \& Pike, S. (2012). Perceptions of visitor relationship marketing opportunities by destination marketers: An importance-performance analysis. Tourism Management, 33(5), 1281-1285.

Tseng, M. L. (2011). Importance-performance analysis of municipal solid waste management in uncertainty. Environmental monitoring and assessment, 172(1-4), 171-187.

Taplin, R. H. (2012). Competitive importance-performance analysis of an Australian wildlife park. Tourism Management, 33(1), 29-37. 